\title{
Ensuring confidentiality and safety of cancer registry data in Kumasi, Ghana
}

\author{
Dennis O. Laryea*1 and Fred K. Awittor ${ }^{2}$ \\ ${ }^{1}$ Komfo Anokye Teaching Hospital, Kumasi, Ghana; ${ }^{2}$ Kumasi Cancer Registry, Kumasi, Ghana
}

\section{Objective}

To discuss the implementation of confidentiality practices at the Kumasi Cancer Registry.

\section{Introduction}

Cancer registration involves collecting information on patients with cancer. Population-based cancer registries in particular are useful in estimating the disease burden and to inform the institution of prevention and control measures. Collecting personal information on patients with cancer requires strict adherence to principles of confidentiality to ensure the safety of the collected data. Failure may have legal and medical implications. The Kumasi Cancer Registry was established as a population-based cancer Registry in 2012. The registry collects data on cases of cancer occurring among residents of the Kumasi Metropolitan area of Ghana. Issues bordering on confidentiality were an integral part of the establishment of the registry. We discuss the implementation of confidentiality plans during the four years of existence of the Kumasi Cancer Registry.

\section{Methods}

The registry has a designed abstraction form which is used to collect data. Data sources for the Registry are all major hospitals in Kumasi providing cancer treatment services. Data sources also include private pathology laboratories and the Births and Deaths Registry. Trained research assistants collect data from the folders of patients. This is followed by coding and then entering into the Canreg 5 software. Coded and entered into the Canreg5 software for management and analysis. After data entry, the forms are filed in order of registry numbers as generated by the canreg 5 software for easy reference.

\section{Results}

Confidentiality of $\mathrm{KsCR}$ data is ensured through the following measures. The signing of a confidentiality agreement by all registry staff. The confidentiality agreement spells out terms for the release of data to third parties in particular but even staff of the various facilities. The agreement also spells out the consequences of a breach of any of the clauses. No direct contact is made with patients during the process of abstraction of data by registrars. The data abstraction forms are kept in a secured safe in the registry office. The computers that house the registry data are password enabled and are changed on a regular basis to ensure security. The Canreg5 software used for electronic data management also has individual profiles with passwords for all registrars and supervisors. The scope of access to Canreg data is limited by the profile status of the respective staff members. Supervisors have full access to all data including summarized reports. Registrars have limited access mostly restricted to data entry. Access to the registry office is restricted to registry staff and other personnel authorized by the Registry Manager or Director. An established Registry Advisory Board is responsible for assessing requests and approval of data from the registry. Where files have to be sent electronically, they are password protected and sent in several parts in separate emails.

\section{Conclusions}

Despite the potential challenges to maintaining confidentiality of data in developing outcries, evidence from four years of cancer data management in Kumasi suggests stringent measure can ensure confidentiality. The use of multiple measures to ensure confidentiality is essential in surveillance data management

\section{Keywords}

confidentiality; cancer registration; Ghana

\section{Acknowledgments}

Staff of the Komfo Anokye Teaching Hospital, Kumasi, Ghana

\section{References}

1. Storm H, Brewster DH, Coleman MP, Deapen D, Oshima A, Threlfall T, et al. Guidelines for confidentiality and cancer registration. Br J Cancer. 2005 Jun 6;92(11):2095-6.

2. Jensen O, Parkin DM, Maclennan R, Muir C, Skeet R, editors. Cancer Registration: Principles and Methods [Internet]. Lyon, France: International Agency for Research on Cancer; 1991 [cited 2015 Jul 28]. (IARC Scientific Publications). Available from: http://www.iarc. fr/en/publications/pdfs-online/epi/sp95/SP95.pdf

3. Laryea DO, Awittor FK, Sonia C, Boadu KO. Three Years of Population-Based Cancer Registration in Kumasi: Providing Evidence for Population-Based Cancer Surveillance in Ghana. Online J Public Health Inform [Internet]. 2016 Mar 24 [cited 2016 Apr 14];8(1). Available from: http://ojphi.org/ojs/index.php/ojphi/article/view/6548

4. Beskow LM, Sandler RS, Weinberger M. Research Recruitment Through US Central Cancer Registries: Balancing Privacy and Scientific Issues. Am J Public Health. 2006 Nov;96(11):1920-6.

\section{*Dennis O. Laryea}

E-mail: dlaryea@kathhsp.org 